\title{
Collapse and Construction of System-Starting from the Disappearance of Smart Phones
}

\author{
Chia-Hong Lin-Liao \\ Department of Creative Design and Architecture, National University of Kaohsiung, Taiwan \\ Email:11ch81150@gmail.com
}

How to cite this paper: Lin-Liao, C.-H. (2017). Collapse and Construction of System-Starting from the Disappearance of Smart Phones. Current Urban Studies, 5, 121-145.

https://doi.org/10.4236/cus.2017.52008

Received: March 9, 2017

Accepted: June 4, 2017

Published: June 7, 2017

Copyright $\odot 2017$ by author and Scientific Research Publishing Inc. This work is licensed under the Creative Commons Attribution International License (CC BY 4.0).

http://creativecommons.org/licenses/by/4.0/

\section{cc) (i) Open Access}

\begin{abstract}
The intention of this study is to point out that the collapse of a system starts with external force (or unexpected force) instead of time. Therefore, the construction of system relies on external force as well. First, this study starts with a brief introduction to the relationship between a system and the structuration theory with structured agents as external force for explanation; second, the correlation between system and external force is established based on laws of thermal dynamics and the structuration theory; and third, the previous theory of us applied to cases like disasters occurring in Kaohsiung, urban planning, traffic configuration and smart phones, and the external forces existing in a system, possible applications and the issue of difference between social and theoretical systems, hoping that this may provide a building block for quantified data and strategy proposal in the future.
\end{abstract}

\section{Keywords}

External Force, Entropy, Time, Structuration Theory, System

\section{Introduction}

Smart phone has long become the communication tool that is extremely popular in Taiwan. According to National Communications Commission (NCC), there are 16.42 million subscribers of mobile network access service by the end of Jul. 2015 as opposed to 5.87 million at the end of Sep. 2011. The latest survey of Innovative Digi Tech-Enabled Applications and Services Institute (FIND) indicates that $65.4 \%$ of people in Taiwan had a smart phone as of the 2nd half of 2014, and this percentage increased dramatically to $86.6 \%$ in 2016 (Institute for Information Industry, 2014). If one day cell phones disappeared from the surface of Earth, many systems built around smart phones, such as contact groups for daily life and office, personal information, daily schedule, photo records and many more, would be devastated, and people' life system would fall apart and 
become disassociated until a new system started to take shape.

Let's look at an interesting example. On a typical morning, a working-class man is on his way to the office and he has his cell phone in one of his pockets for easy access. When he is in office, he places the phone on his desk and starts charging it, and puts it back to a pocket on his way home at the end of day before he charges it again at home. This daily routine happens day in and day out and eventually the cell phone becomes an indispensable part of working-class life as a convenient communication tool. One day, it is very warm and he takes off his vest and puts it in his brief case along with his cell phone. All he has to worry about is to prevent the phone from falling out of the brief case. However, it suddenly gets cold and he takes the vest out without realizing that the cell phone is in the brief case as well. Tragically, the phone falls out of the brief case on the floor and breaks into pieces. There are so many data stored in the cell phone and the office group in Line is essential for his office works. Therefore, the working-class man rushes to company A to have the cell phone fixed. However, the service guy tells him that the cell phone is a product of company B and that he has to go to company B for service. Unfortunately, company B does not open for business that day. The working-class man feels that it seems hopeless to have the phone repaired and he decide to buy a new one. Since he does not carry the Line password with him, he has to get a cell phone very quickly to answer questions passed around in the office group, and the service guy of company A tells him that he can reset Line and recover the data (which is a rookie mistake of misunderstanding). The working-class man takes the service guy's advice and resets Line only to find out that all previous data are gone and he has to invite everyone else to join his Line office group.

Basically this is the highlight of what every one of us may encounter in daily life. None of these would have happened if a single step of putting the cell phone in his pocket was added to allow him to bring the cell phone back home safely and sound and enjoy this device of modern convenience at the comfort of his home. However, from an idea of "I think", an action of "putting the cell phone in the brief case" to a sudden event of "I forgot", basically there are several "broken" parts in this system of supposedly bringing the cell phone back home safely and sound and that leads to the "deconstruction" as the cell phone breaks into pieces. When this working-class man tried to have the cell phone repaired in a "short period of time," he follows the "existing service channel" and at the end decides to "buy a new phone" in order to reconstruct the "original communication" system in a "short period of time." Because little does he know, this series of actions results in the deconstruction of the old system, and the new cell phone starts a new system. This demonstrates how a system is built, and it is always the "external force" at work. It is about the steps of how you want to achieve a goal instead of the "time" you want to achieve.

Emphasis on time has become a part of the practice for emergency repairs, disaster rescue, safety control and dynamic simulation. However, we may have to dig deeper as what time really means. Do we need time or a method in daily 
life? Is time a necessity of life or just limitation? Is the goal to complete a task the end effect or being fast? Do we get the correct answer if we simulate dynamics based on time? When time is considered as a constant or fixed value, does time mean little or even nothing for the calculation of external force or acceleration? If we try a way of thinking like this, chances are that we may find lots of calculation formulas deviate from reality, including inaccurate prediction of a political voting result, high accident rate even with traffic signal control, or failure to make an accurate economic prediction based on behavioral economics. So many mistakes happen in daily life, and the strategies to prevent them do not seem to perform as expected. Does that mean the equations of laws of physics require changes? What is the correlation between time and external force? The idea of considering time as a constant may provide a key points as food for thoughts.

An event that happens in our daily life, the smart phones, is introduced to associate and elaborate the idea against the dynamics of time; i.e. time is a constant or can be considered as a factor of limitation. Real-life examples are investigated to prove that external force is the main factor that determines how things develop. The story of a working-class person who has his cell phone serviced allows us for the understanding that systems exist in the everyday life. Any task with a time-related purpose may lead to increased risks and reduced benefits; any time-based formula should be given a chance to be examined and to make it complete.

It would be a new attempt to explain the phenomenon of external force mentioned above with the integration of the structuration theory. Proposed by Giddens, the structuration theory is an explanatory framework that goes beyond the dualism of structure and agency. It provides both theoretical and empirical social insights in terms of interpretation method, human agency and the timespace context associated with this society (Moos \& Dear, 1986a: 371). There have been a number of empirical studies in the academic society. As a result, this study is an attempt to start with the disappearance of a smart phone to propose an overall explanatory framework of how the structure and agency work together for production, reproduction and conversion for many complicated issues from the various analytical points of view of the structuration theory. For methodology, the implication of external force in social practice is highlighted using the calculation concept of thermodynamics and structuration theory.

Therefore, this research focuses mainly on highlighting and expressing the importance of external forces on the outcome of things processed, and referring to the law of thermodynamics, a calculation method for the practical community to analyze external forces is derived. Because whether it is the physical and chemical laws in the academic sense or the disaster relief and task assignment in the practical sense, time is often viewed as the main variable in the changes in results, for example: the physical law of acceleration, 72-hour golden rescue window, etc. However, this type of judgment are oftentimes distorted, we can see this type of result in the verification of the case at Kaohsiung Harbor City within this research. Academically, instead of simplifying it into only being influenced 
by time, a review and redefinition on the variable expansion of the law might be needed; in the assignment for rescue tasks and the promotion of policies, the level of influence of the practical external forces must also be considered in order to obtain better solutions and results.

\section{Literature Review: System and Structuration Theory}

To quote von Bertalanffy (in Miller 1965), "A system is a set of units with relationships among them". McConnell (1977) states, "Anything that is itself alive-or that is made up of living things-can be thought of as a living system of some kind. You are alive; so you are a living system. But your family is made up of living organisms, hence your family is also considered a living system" (Frank \& Mark, 1981).

For this, it is similar that every organ, tissue and cell in our body need nutrition and oxygen to stay alive, and blood is the transportation system that transports these two to every cell. This is how the social life system works. The 5 element theory of Chinese philosophy that everything has something to work for and against it is talking about the causal correlation of system and the concept of closed feedback and dynamics in the natural system. It is clear in the following literatures of system thinking and social agency that the operation procedure and correlation discussed in a system are not just simply mentioning of a closed or open state, which is an important hypothesis of this study to be investigated in the following chapters.

\subsection{System}

First, all conceptions of "system" involve a set of units and their interrelationships. Since any binary relation has a natural representation as a graph or digraph, the points being the units (people, groups, or larger aggregations) and the lines the relations between them, a graph-theoretic approach immediately suggests itself. Secondly, systems are viewed in all of the above quotations as possessing a hierarchical or nested structure. These two ideas are precisely the motivating forces of our approach (Frank \& Mark, 1981).

Therefore, Systems thinking is not General Systems Theory nor soft systems nor systems analysis, although it has elements in common with all of these. Furthermore, systems thinking is not the same as chaos theory, dissipative structures, operations research, decision analysis, or what control theorists mean when they say system dynamics, although, again, there are similarities in subject matter and methodology. Systems thinking is also not hexagrams, personal mastery, dialogues, or total quality (Barry, 1994).

From the dialogue between two esteemed scholars above on systems, it is obvious that the structural correlation of system is not a relationship of time. In their study on the correlation dynamics of Kaohsiung City and Harbor, Lin-Liao (2014) started with time as the basic assumption of dynamics and considered that the harbor and city together are a comprehensive system with an intricate causal relationship. In their study, system dynamics analysis was introduced to 
investigate complicated issues such as population, employment, environmental pollution and resources and the concept of feedback system, and the result of correlation dynamics of Kaohsiung City and Harbor was proposed. Lin-Liao (2013) correlated the management, economy and power system with feedback based on the same logics. The concept of feedback system is to create a closed causal loop of mutual correlation, while the system dynamics is to design a unique set of symbols to describe a system by considering substance and information in a system as movement of fluids. For basic elements and associated representation, the system parameters or coefficients are characterized using flow potential equation, flow rate equation, auxiliary equation and constant variables (Zhang, 2006).

The system dynamics is similar to the heat engine in thermodynamics, both of which are closed circulation systems. It is a system that goes through a series of conversions and at the end returns to its initial state. This process is called a cycle. In certain conversions, the heat engine exchanges energy with large systems, and stays in a constant state by absorbing or releasing a certain amount of energy. In the concepts of thermodynamics, entropy is considered the loss of order in a system, i.e. the measurement of how disordered a system is. In 1865 , Clausius defined the increase/decrease of entropy in a thermodynamic system is the total amount of energy used in an isothermal process in a reversible procedure $(\delta Q)$, and expressed as $\Delta S=Q / T$, which means the "feature of a system to develop into the most stable state internally free from external interference." When a system is converted under external force, for example, temperature and volume are defined as reversible, the system will remain very closed to equilibrium called "quasi-static process." Or, this conversion is irreversible.

Ironically, however, systems are not always closed and there is not always feedback or equilibrium. It is not even as simple as the difference of being reversible and irreversible. For a system, in addition to the discussion on the existence of time, human life involves social forces, which may include political, economical or other sudden events or the influence of the entropy flow (diS) as mentioned in physics. Depending on whether a system strictly fulfills the principle of superposition and whether there is entropy flow in a system, there are linear system and nonlinear system. If a $3 \mathrm{D}$ rectangular coordinate system is built based on the properties of open-closed, balanced-unbalanced, and linearnonlinear, there can be as many as 8 types of structure for a typical system ( Ku \& Zhang, 2005).

In addition to the applications in equations of physics, the concept of system is often found in our daily life and getting increasing attention in every aspect. It is the purpose of this study to propose a sound logic explanation with external force as the primary variable and define a mathematic model of an abstract system by referring to thermodynamic theories.

Clearly, any such abstract formulation must be judged according to two criteria. It must adequately describe the existing body of data in the field, i.e., it must be consistent with the definitions proposed in the existing literature. Also it 
must provide a firm basis for realistic and verifiable predictions, i.e., it must be testable empirically (Frank \& Mark, 1981).

\subsection{Structuration Theory}

The sociologists mainly involved in exploring structure and momentum include Georg Simmel, Talcott Parsons, Bourdieu. Simmel believes that as the society evolves, human knowledge will continue to develop (Simmel, 1905); however, in order to make life and trade more convenient, the traditional society is now gone forever, such as production of currency so as to highlight their differences in behavior (Levine, 1972). Parsons believes that a society only has four basic needs to fulfill its functional requisites, including obtaining the objective, adapting to the environment, integrating the different parts of the environment into one, and controlling deviant behaviors, in order to perform its functions, in other words, this is how to maintain its order and stability (Parsons, 1937).

Key words, such as habitus, field, and capital, brought up by Bourdieu (1984) have brought much attention (Patrick, 2009: p. 209). Bourdieu's work attempts to reconcile structure and agency, as external structures are internalised into the habitus while the actions of the agent externalise interactions between actors into the social relationships in the field. And having revealed the dynamic power relations in the social life (Bourdieu, 1984), he believes that different levels of society, economy, and cultural capital will make up a "class structure," and these attributes are shaped by the interests of those in dominating class statuses (Bourdieu, 1984: p. 66). Bourdieu believes that when doing research, one eye should be used to constantly reflect on one's own habits, which are the temperaments produced through the long-term social and institutionalized training. Through these constant reflections, one can know one's own prejudices (Bourdieu \& Wacquant, 1992: p. 68-70). Basically, the view of Giddens on being reflective is consistent with his.

The differences in the analysis of social structure between Bourdieu and Giddens are on the classification and meanings of structure resources and systems (William \& Sewell, 1992). Gidden presents a developed attempt to move beyond the dualism of structure and agency and argues for the "duality of structure"where social structure is both the medium and the outcome of social action (Jary \& Julia, 1991). Giddens's "agency" approach also implies the possibility of resistence, as power appears through action instead of inevitable historical relations. Bourdieu's "theory of practice" predates Giddens' structuration theory, but there are a number of similarities, including conceptions of agency and structure and concern for reflexivity (Gaventa, 2013).

The structuration theory that Giddens presented in 1983 fused the perspectives of different sociologists and those in different positions and deeply explored the issues of the structures and spatial interactions of human behaviors. The conception of system, structure, and agency in structuration theory provides an enticing manner of understanding society (Moos \& Dear, 1986b: p. 351). Thus, there is an anticipations find a strong echo, who argues for a social science 
method which explicity incorporates a "hermeneutic circle": "to understand and explain social phenomena, we cannot avoid evaluating and criticizing societies" own self-understanding (Moos \& Dear, 1986b: p. 355). Furthermore, Moos and Dear (1986b) used strategic behavior analysis to understand the structure of events, or understood the goal of the event through the interactions of the agents during the non-stages.

Taiwan's research on social strata mainly follows that of the U.S., and obtaining the introduction of the model due because of the early status has brought about the path analysis of a great amount of structure models, which is then followed by new structuralism, and, later on, mobility tables were used to analyze the research orientation of flow patterns (refer to Tsai, 1997). The two main elements, "mediate" and "proximate," in the structure of class relations proposed by Giddens have helped the remake of class relations (Hung, 2000). Also, this includes personal action and structural interaction, which can definitely bring a new theory and orientation to those eager to solve the fuzzy issue between individuals and structures and to analyze the complex relations in Taiwan's rapidly changing society (Tsai \& Lin, 1999). Therefore, this study is intended to derive a possibly different system result with various scenarios in Taiwan as the case study by using a system equation with time as a constant and integrating the correlation arguments of the structuration theory.

Therefore, if the system and structured theory are integrated and explained, it would have a complementary effect. The system tries to organize and institutionalize the mathematical derivation or the process of things. This idea of external forces exists in the changes in temperature and volume in the concept of thermodynamics. The structured theory tries to explain the changes caused by the potential factors within the society. Both place a special focus on the external and internal causal relevance and explain the influence of external forces from different perspectives; therefore, in the construction, cycle, and calculated derivation of the system and the discussion on dynamic structure, we will try to integrate the theories related to both sides, as it can convey the influence of external forces and can also verify the statement in this research. In addition, because this research method is quite innovative in terms of related academic research, there's positive meaning and innovative value for follow-up academic discussion.

\section{System Construction and Circulation}

The expression of "Study for Correlation Dynamic Analysis of Kaohsiung Port City" proposed by Lin-Liao (2014) describes the representation of difference systems. A system is a step-by-step collection of factors as widely scattered factors are integrated and acquired one after another. The port and city are entities of different natures in a system, like yin and yang, male and female or good and bad. Correlation is to gather factors of no correlation or at the same position together and form an entity. Dynamics is the effect generated by external force on factors at various points of time. The generation of external force can be a sud- 
den occurrence or deliberate increase or decrease of force internal to the original system. Analysis is to find out the layout of factors that are not correlated with one another. This term can be used to describe the process of system construction and circulation, and the possibility of its applications in temperature, entropy and thermal energy in thermodynamics.

Thermodynamics is the study of change of material states and energy conversion in thermal phenomenon. It is focused on the equilibrium of substance and the physical and chemical processes of quasi-equilibrium state. Thermodynamics comes with 4 laws, including the definition of the physical measurement of temperature, the existence of internal energy as a physical measurement, physical measurements involving the introduction of the irreversible process of temperature and entropy, and impossibility to cool a system down to absolute zero with a limited process.

First, absolute temperature is used in thermodynamic equations. A certain amount of heat, $Q^{\prime}$, is extracted from the first heat source. The corresponding temperatures are $T$ and $T^{\prime}$, and therefore, $Q / T=Q^{\prime} / T^{\prime}$. Assuming a cycle of an arbitrary heat engine, a series of heat, $Q_{1}, Q_{2}, \cdots, Q_{N}$, are extracted from $\mathrm{N}$ heat sources and each of them has a corresponding temperature, $T_{1}, T_{2}, \cdots, T_{N}$. Assuming that the heat is positive if received by a system and negative if released, then we have:

$\sum_{i=1}^{N} Q_{N}^{\prime} / T_{i} \leq 0$, where the equation is still valid if the cycle reverses (Wikipedia, 2017).

Say an additional heat source of temperature $T_{0}$ is introduced to a Carnot cycle with $N$ heat source. If heat $Q_{j}$ is transferred from heat source $T_{0}$ to $T_{j}$ in $j$ cycles, it is learned from the absolute temperature equation defined previously that the heat transferred from heat source $T_{0}$ in $j$ cycles is: $Q_{0, j}=T_{0} Q_{j} / T_{J}$. Heat always travels from high to low temperature if the cycle is irreversible. Therefore, $Q_{j} / T_{j} \leq Q_{j} / T$; however, if the cycle is reversible, the system will always approach equilibrium. As a result, the temperature of the system has to be consistent with that of heat source it is in contact with. In such a case, $\mathrm{T}$ may be used in place of all $T_{j}$ s. For this specific case, a reversible cycle can continue to transmit heat, $\oint \Delta Q / T \equiv \oint \mathrm{d} S=0$ (reversible cycle) (Robert \& Jack, 2006; Wikipedia, 2017).

The second law of thermodynamics says that the total entropy of an adiabatic system does not decrease automatically, which means that the change in entropy depends only on the initial and terminal states. From this the entropy of a system at any state of equilibrium can be defined. By selecting a reference state, $R$, with its entropy defined as $S_{R}$, the entropy at any equilibrium state, $X$, is: $S_{X}=S_{R}+\int_{R}^{X} \frac{\delta Q}{T}$ (Wikipedia, 2017). In a certain environment (assuming adiabatic), once the system reaches the maximum entropy, no more work can be produced. Temperature is a very important variable and factor of influence in thermodynamics. Therefore, if temperature $(T)$ is considered an external force 
of a system $(F)$. total heat $(Q)$ as system $(s)$, and entropy $(\Delta S)$ as the system change due to external force $(\Delta s)$, then it is assumed that a reference state, $R$, is selected for the system. With the system change at the equilibrium state, $X$, the equation is developed as

$$
s_{X}=s_{R}+\int_{R}^{X} \Delta s / F
$$

For the measurement of entropy in an adiabatic process, the heat capacity at constant volume and pressure (expressed as $C V$ and $C P$, respectively) in the thermodynamic state is simplified. The relationship between heat capacity, entropy, $S$, and temperature, $T$, is: $C_{X}=T(\partial S / \partial T)_{X}$. By calculating the change in entropy using definite integral, it is determined: $\Delta S=\int C_{X} / T \mathrm{~d} T$. If the pressure at the reference state is the same as that at the final state:

$S(P, V)=S\left(P, V_{0}\right)+\int_{T\left(P, V_{0}\right)}^{T(P, V)} \frac{C_{P}(P, V(T, P))}{T} \mathrm{~d} T$ (Wang, 2003; Wikipedia, 2017). Here if the entropy measurement and equation, $s_{X}=s_{R}+\int_{R}^{X} \Delta s / F$, from the previous adiabatic process are substituted and pressure $(P)$ is considered as a natural external force of system $(N)$, volume $(V)$ as a social scenario of system $(C)$ and system change as $(\Delta s)$, and assuming a reference state, $X$, is selected for the system, then the equation of system change at the equilibrium state, $X$, is:

$$
s(N, C)=s\left(N, C_{0}\right)+\int C_{N}(N, C(F, N)) / F \mathrm{~d} F
$$

Entropy is a level of disorder, changes caused to a system by the introduction of external force. The equation above shows us that the system will move towards different directions due to the difference in time. In addition, the uncertainty of the existence of external force will lead to that of the result of system changes, and in turn a series of system problems are generated.

Let's go back to the working-class man who tries to repair his smart phone. The man goes back to his office after the ordeal. One of his coworkers suggests that he has to return to default settings in 24 hours to recover the Line group data. With this suggestion in mind, the man goes to company $\mathrm{C}$ in the vicinity of his place for repair. However, company $\mathrm{C}$ tells him that he should not have reset at the first place. He should have stayed with the old Line password or selected transfer to new mailbox. Once a new mailbox is set, the old Line group information is gone for good. The answer from company $\mathrm{C}$ closes the door for the recovery of Line group information. Such a result of system analysis comes from hidden external forces, which involve the difference in the recognition of information for everyone in the system and thus lead to influence on the system. This is similar to the assumption of traditional economics that does not apply to the pattern of behaviorally economy. It is not about dealing with time.

Sendhil \& Richard argued that the classic economics assumes that people are rational and on the constant pursuit for maximum profits. However, people are not always rational as some of them are passionate, biased and impulsive. The center of economy is the individuals who are predictable and prone to making mistakes. What we need, however, is an economical model that is built around 
real people before it is able to help individuals, companies and governments to make better decisions (Sendhil \& Richard, 2000). This is the same case when Conte talked about the moral explanation of politics and history, as he believed that morality should be understood as the "ideal orientation for thoughts and behaviors." Kang's observation indicates that the behavioral presentation of the general public and even political figures is more controlled by ignorance, childishness and desire than guided by morality and ideal (Kant, 1996). That is to say the system of social life does not just exist in the difference of physical calculation of historical time. A system like this is superficial. The power of civil society that is internalized is what drives the constant development of human being, which is one of the reasons top introduce the istructuration theory to this study.

\section{Agency and Structure of System}

In a new and interesting development relating to the concept of generic structures, Richmondz isolates what he calls "atoms of structure," defined as "primitive feedback loops which generate the behavior of basic processes." According to Richmond, five atoms of structure have been identified thus far: self-generating production processes, self-generating flow-through processes, explicit goal-seeking processes, non-self-generating production processes, and co-flow processes. These "atoms of structure" are related to the forms of commonly recurring rate/level structures outlined in Richardson and Pugh (1981: p. 133-158) (Paich, 1985).

Structuration theory is a bold and new attempt at resolving a great conflict in social theory. In the following sections we outline the key elements of structuration theory which are employed in this analysis: structure, system, structuration; agency; the duality of structure.

1) Structure, system: Giddens believes that structure is the structural properties that allow the "binding" of time-space in social systems. These properties make it possible for similar social practices to exist across time and space and that lend them "systemic" form. With "structural properties", the present structure specifically exists in the time-space social practices and guides the actors with cognitive ability to act (Giddens, 1984). This is what Giddens defined as the social rule (see Cloke et al., 1991: p. 93-113).

2) Action, acts, and agency: human's action is a continuous process or flow of involvement rather than a combination of acts. Like cognition, purposive actions are not composed of a group or a series of single and separated intentions, reasons, or motivations. They are even accustomed to monitoring the social and physical properties of their own environment (Giddens, 1984: p. 29). As for the explanation of agency, Giddens believes that agency refers to individual act and action as a series of logical steps: "I think, therefore I do". However, not all actions are defined as purposive, which means that not all acts are carefully arranged to fulfill the purpose in his or her mind. Human agency is the capabilities of human to control and their related activities or behaviours (see Cloke et al., 
1991: p. 99).

Giddens believed that duality of structure comes with three types of interactive factors, namely agents, such as communication of meanings, execution of power and constraint to behaviors, which lean toward the recessive side; structural interactions, such as mediation and implication (common intention), domination (formation of force) and legislation (outcome), which lean toward the dominant side; and description of how a social system if created based on the cycle of recursiveness and mutual feedback. Giddens indicated that it is the structure that allows the structured characteristics of "binding" in space-time exist in a social system. A institution is the embodiment of social practice as well as the social system built by practice (Hung, 2000: p. 111). The three primary concepts are mutual feedback or reflexivity, recursiveness and regionalization.

The idea of reflexivity is that the production of social life is the inertial result of segmental knowledge and ability (Gregory et al., 2009). It is the constant reflection of one's existence and the continuous being of surrounding world; whereas the core of recursiveness is that the structure consists of media and social practice. The rules and resource of a social system leads to the formation of social practice trough implications, domination and actors of legislation structure, and these structures in turn reproduces or converts through social practice, allowing agents to appear in the internal structures repeatedly; and regionalization is the continuum of social life generated by the interactions of presence and non-presence in the same space-time (Gregory et al., 2009), thus allowing the connection between society and system integration to interact through regional organization of space-time; i.e. the members of a community or society are controlled by the regionalized pattern led by the path of space-time in their daily activities.

Basically, Giddens thought that structure and agent cannot be completely and absolutely separated (Figure 1). For example, it is normal that the lifecycle of a
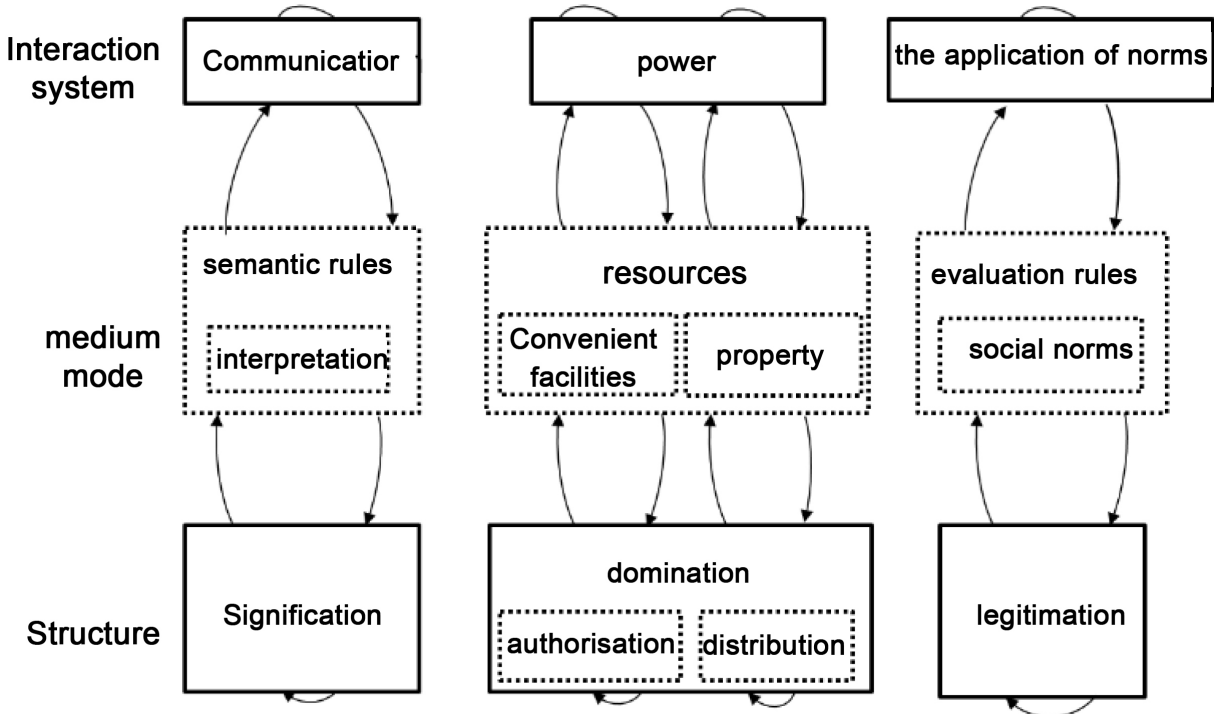

Figure 1. Diagram of social structure, social interaction, and medium mode. Source: adopted from Gregory et al. (2009). 
smart phone is approximately 3 years from the acquisition of materials, manufacturing to delivery. The structure generated from its lifecycle can be considered a reference for market supply. However, the market structure is not stable, used or supplied as expected due to the many external damages generated. The key is the manipulation of agents. Through the communications of agents (e.g. suppliers and users), a structure of propaganda takes shape in an appropriate way of expression. The agent of power execution leads to the authorization structure of distribution of domination through the resource of increased charging; and the agent that executes constraints on both sides creates a structure of contract via the norms agreed upon.

Thanks to the philosophical discussion on the institution space-time in the structuration theory, a deeper understanding on the structure factors at each of the stages is obtained. Therefore, an attempt is made to analyze and calculate the existence of a pattern in the cases of rescue of disasters that frequent in Kaohsiung, urban planning, traffic design and the process of cell phone repair. Giddens' analysis model is used to investigate why the cases mentioned above are not easy to solve, discover the correlation between systems, describe how an agent capture the social rules and resources in a system structure in the process of social interactions with systems while changing the institution through the process of social practice.

First of all, according to Giddens' structuration theory, it is assumed that the communications of external force (agent) $=$ cooperation; power $=$ economic or political force; conditioning = restraining force; implication of system (structure) $=$ system of multiplication; domination $=$ system of reduction; and legislation = system of maintenance. Therefore, the explanatory structure proposed in Giddens» structuration theory consists of communication of meanings, execution of power and sanction on actions. A structure is the mediation and result of actions that are organized repeated on themselves. The structural characteristics of a social system are the production and reproduction that roll in behaviors constantly and repeatedly (Giddens, 1976: p. 122). In the context of time, the recurrence of social practice will definitely be sedimented into an institution. With the system under the intervention of external force, it is assumed that the systems of multiplication, reduction and maintenance will be generated.

As shown in the process the working-class man deals with his cell phone, it is obviously impossible to recover his Line groups, and he has to start all over again by inviting his friends to join the groups. Having experienced the ordeal, he decides to have the screen attached with protective film. However, little does he know, company $\mathrm{C}$ accidentally leaves air bubbles under the film and tells him that it has to be replaced with a piece of new film. He will be notified with a text message. The man rushes back to his office only to find out that the credit card charging does not work since he has lost his ID. He keeps looking and reflecting where the ID might be lost until company $\mathrm{C}$ calls him about his lost ID, which means he has no choice but having to visit company $\mathrm{C}$ again at the end of day. When a system becomes sedimented and an institute takes shape through con- 
stant feedbacks, he will create a new system and try not to travel the same path again. Granted that there are positive and negative external forces out there, and the goal may even be incorrect, causing chaos in the system (for example, the working-class man rushes to have his cell phone repaired to save time). These mistakes should be avoided to minimize the external force influence of behavioral economy, or systems evaluated thoroughly to allow those evaluated to become normal.

System and structured theory value intention (i.e. the concepts or thoughts of human beings), because the behavior of people determine the occurred or caused outcome. Through the actual occurred results in Kaohsiung, this research explores future practical occurred results or ways to resolve. Its represented meaning is in explaining that system exists in the life of human beings all the time, while external forces (or called thinking mode) will determine the results of things, loss, or benefit, and not the length of time.

\section{Case Study}

The "duality of structure" proposed by Giddens-i.e. social structure is the result of mediation and social action (Jary \& Julia, 1991) - discusses the structure of human behavior in depth and the interaction with space. The hypotheses above, analysis equations and the structuration theory are applied to the following practical life systems occurring in Kaohsiung for this study, as to validate the practical feasibility and theoretical explanatory power.

\subsection{Land and Traffic Planning of Kaohsiung Port City}

The business districts in city downtown all across the globe usually consist of the primary types of life elements as well as the areas of use for harbor properties. Some of the downtown business districts still retain the powerful functions of downtown despite the fierce competition from port city. Los Angeles is a typical example of multi-core metropolis. The traffic of a port city and urban land space structure are closely correlated to the industrial characteristics. The city traffic will be jam-packed when most people are forced to walk every day. When cargo deliveries are frequent, the traffic of people and cargo must be complicated at the harbor. The following are some issues facing Kaohsiung as a port city:

1) Traffic congestion: in 1990, the traffic was moving closely at the assumed average speed of 10 miles/hour $(16 \mathrm{~km} / \mathrm{h})$ at peak hours in central London $(\mathrm{Pa}-$ cione, 2009). According to Environmental Protection Administration, Executive Yuan (2002), the average speed of travel is $19.16 \mathrm{~km} / \mathrm{hr}$ in urban Kaohsiung (average driving speed of $24.88 \mathrm{~km} / \mathrm{hr} / \mathrm{travel}$ ). The three large cities with port facilities in Taiwan have the similar congestion level to the city downtowns in Europe and America in terms of average speed of travel.

2) Environmental impact: traffic is a major source of air pollution in cities. According to Environmental Protection Administration, Executive Yuan (2002), the average coefficient of emission in urban Kaohsiung is $6.53 \mathrm{~g} / \mathrm{km}$ for CO, 1.62 $\mathrm{g} / \mathrm{km}$ for THC, $0.13 \mathrm{~g} / \mathrm{km}$ for $\mathrm{NOx}$, and $54.03 \mathrm{~g} / \mathrm{km}$ for $\mathrm{CO}_{2}$. If we look at the to- 
tal emission of pollutions from motorcycles, it is estimated that motorcycles contribute 29,104 tons/year of CO, 7220 tons/year of HC, 579 tons/year and $\mathrm{NOx}$, and 240,812 tons/year of $\mathrm{CO}_{2}$ for the total emission of pollution in urban Kaohsiung.

3) Accidents: most transportation studies indicate that traffic accidents are a very common phenomenon for the urban traffic system. Truck overloading and the blind spots around these trucks contribute to the increased risks of accident.

4) Parking difficulty: it is challenging to find a parking spot at most city downtowns. This is a common headache when one tries to park since most people want the easy and quick access to city downtowns. However, it is impossible to provide a parking spot for everyone who wants to park.

5) Frequent road damages: trailers and trucks account for at least $40 \%$ of traffic on the roads surrounding a harbor. The weight of heavy vehicles, frequent overloading and suffocating traffic result in much higher expenses for road maintenance, removal of old pavement and installation of new pavement that the average cities. In addition, there are the complicated networks of buried pipelines, the pipelines have to be dig up for maintenance, and the manhole covers have to be made flush to the road surface. These road works often lead to complaints and therefore have to be conducted a consolidated projects.

The equation in Section 3 is used for this case. It is assumed that the external force of system $(F)$ is the positive and negative comments from Taiwan International Port Corp. and local governments. The influence of the economical needs of port, local traffic and public power of environmental quality is studied on the planning and development of roads surrounding port areas. When the external forces are equal, the change of system caused by the external forces $(\Delta s)$ is 0 . In 2016, the reference state is $R=1$, equilibrium state is $X=1$, the system is $s_{X}=s_{R}$, and, therefore, the issue of port city road development is to maintain status quo; i.e. elevated roads are to be developed for the traffic needs of port area. Similarly, for the process of change in a closed system of absolute external force (i.e. the adiabatic nature of entropy), if there is no exchange with the outside world, the system change will only be subject to the external force of local natural environment $(N)$ and social scenario $(C)$ without the intervention of central level or international environmentalist groups. The planning and development of roads surrounding a port will grow and decline under the influence of local environmental concerns and people's perceptions rather than the consolidation of the points of view on both sides due to the extension of time for negotiation. The maximization of social benefits is unlikely without the understanding of external force (local environmental concerns and people's perceptions).

Based on the analysis in Section 4 using the structuration theory, it is assumed that Ministry of Transportation and Communications has reached an agreement with the local government after thorough communications, and there will be the multiplication of system effects in terms of the mutual prosperity of port and city and the road development. If the intervention of economic or political power is introduced, the effects generated for the system may be reduced or even 
work against the system in the form of public protest or disagreement on the part of local government. If the path of legislation and standard procedure is followed fir the review of road development, the balance between the comments for and against the issue will lead to the maintenance of the existing system or one with somewhat disputed road development.

There are problems to deal with at difference stage of urban transportation system, including new infrastructures to satisfy the growing needs, and nontransportation issue of traffic. However, port roads are designed as the guidance of traffic, which is different from the citizen-oriented urban development logics. The traffic congestion of transportation access road network in urban Kaohsiung is created due to the inherent insufficiency of road systems and the soaring demands for cargo transportation, and the large demands for cargo transportation come from the Port of Kaohsiung. For the cargo transportation issues created by Kaohsiung Harbor, the key is the poorly designed road network hierarchy that results in overlapping functions of road service. To improve the service performance of the outward transportation system in urban Kaohsiung, the priority is to deal with the cargo transportation inside and outside of Kaohsiung Harbor and improve the service level of the major outgoing roads. A good way to do so is to promote a transportation diversion plan through engineering means in order to strengthen the traffic service functions of urban Kaohsiung. According to the discussion in Sections 3 and 4, this will not be just limited to accelerating traffic and developing accompanying strategies.

\subsection{Public Opinion, Urban Planning and Traffic System-Qieding 1 - 4 Road of Kaohsiung City}

"Power" is the ability of an individual or group to impose influence on the behaviors of others, as well as a socially approved procedure (e.g. democratic election) and a selection to be assigned or of personal authorization. Power can be executed through social pressure or persuasion or even by economy or force. The result of power struggle is often who gets what, when and how to obtain the system of governance. Therefore, the government is playing an important role of power execution in the distribution of social benefits.

Social benefits are always the center of issues that the public deals with and cares about. The general public receives benefits, the government gets benefited from it, and the balance of power is achieved and everybody gets to do his/her part. In principle, the government's governance, its accompanying role and ability include the integration of power at the central government level, encouraging people to participate in decision making, approaching people, fighting for budgets for city interface governance and management capability, and communication channels that are high-performance and diverse. It should allow the voice to be heard for local concerns and provide the public service and function of a city. The dispute over the development of Qieding 1 - 4 road in Kaohsiung City is one of the issues of social benefits that are commonly seen in the international community associated with economic development and environmental conser- 
vation. The role the government plays in the public opinions, urban planning and traffic system is a crucial challenge in city governance.

The Qieding 1 - 4 road runs through the Qieding wetland which was one of the six major salt fields during the Japanese colonial days. Seawater was introduced from the neighboring Xinda Port to the salt field for salt making. The salt field was eventually closed due to the increase of human labor costs, and sold to the then Kaohsiung County Government in 1987 due to the development of high sea fishing harbor at Xinda. Qieding district is located north of Kaohsiung City by the sea. People made their living by fishing and making salt in early days. The only link to the outside world was Route Tai 17 at the edge of the district. With the downfall of local industries and the need for connection between settlements, the district is in desperate need for an access road for local development and travel safety.

For this, the City Hall added the Qieding 1 - 4 road in the urban development plan in 2002. However, the Qieding wetland (the part that was used to be the salt fields) was designated as a "national important wetland of local level" in 2007 by the Construction and Planning Agency, Ministry of the Interior. The development was pending due to the environmental protection issue. Without the road to bring tourists and business opportunities, Qieding was isolated and urban development stopped as lands were idle, local people started to leave and local development was put in hibernation. In order to improve the current status of the wetland and create a habitat friendly to water birds, the City Hall started to build earth embankment at the Gong 12 area north to the 1-1 road to regulate water levels, allow the pools of water to flow, reduce the loss of water and increase biological resources. At the same time, Gong 15 was developed into an environment for habitation and reproduction of water birds (see Figure 2 for locations).

The equation in Section 3 is used for this case. It is assumed that the external force of system $(F)$ is the positive and negative comments from Taiwan International Port Corp. and local governments. People impose their influence on the development of 1 - 4 road in the forms of voting and information power (e.g. letters to international media or Facebook campaign). When the influence of external force is equal, the system change due to the external force $(\Delta s)$ is 0 . Assuming that the reference state is $R=1$ in 2017, balance state $X=1$, system $s_{X}=$ $s_{R}$, and the issue of $1-4$ road development is to remain status quo (i.e. no development). The building of a new system is not possible until the influence of environmentalist groups dwindles or disappears due to a mutual consent. Similarly, if there is no exchange of external force with the outside, i.e. no intervention from international media and environmentalist groups, the system change will be subject to the local natural environmental external force $(N)$ and social scenario $(C)$. The issue of developing 1 - 4 road will go up and down in the influence of people rather than avoiding dispute or achieving smooth integration due to extension of time of negotiation. More mistakes will be created due to lack of understanding about what people think. 


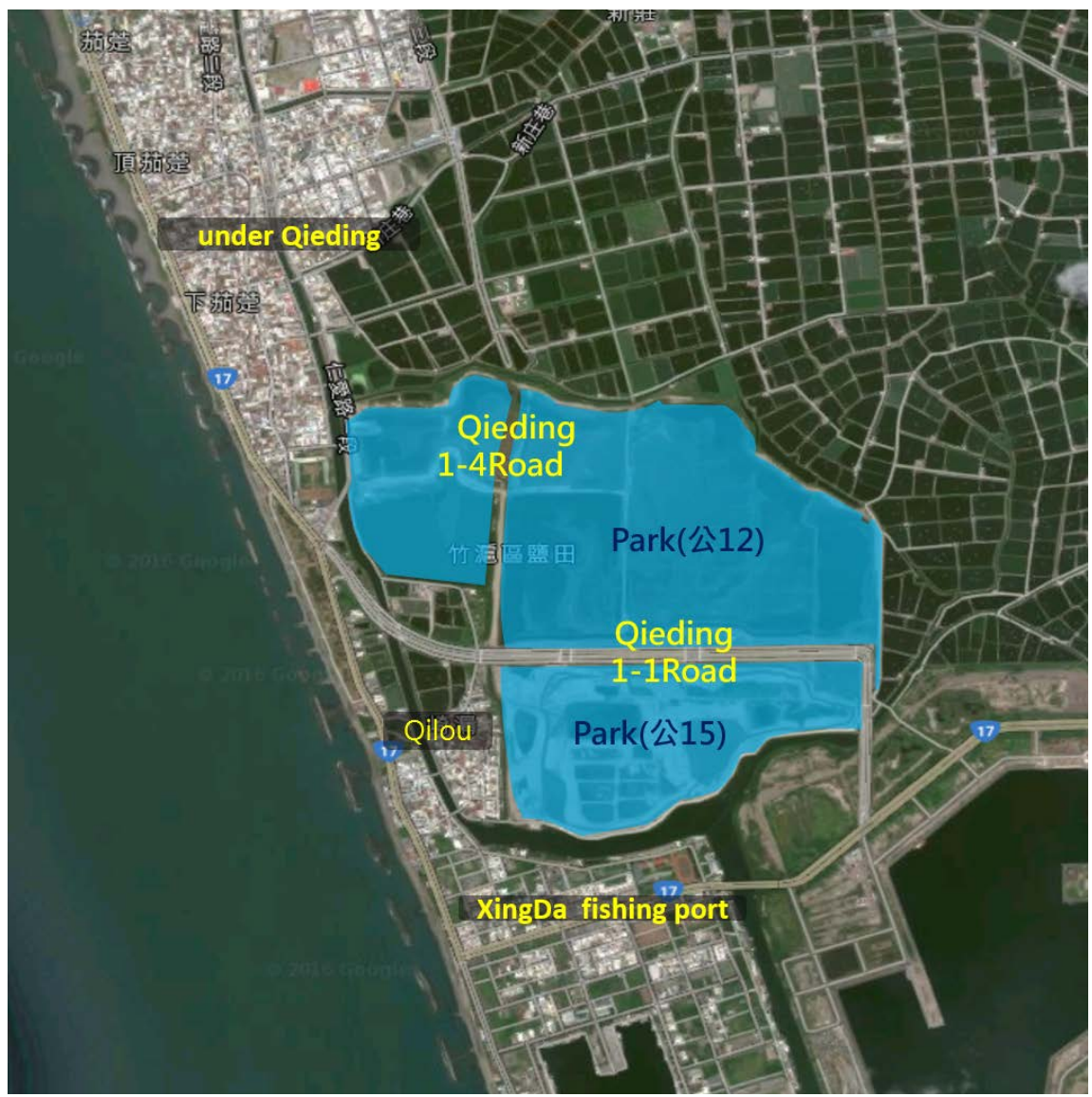

Figure 2. Association between Qieding 1 - 4 road and the wetland.

With the structuration theory in Section 4, it is assumed that people and the environmentalist groups have reached an agreement, and there is the multiplication effect for the system in terms of cooperation for the ecological settlements and road development. If the power intervention of economic or political force is introduced, the effect will be reduced or even work against the system; i.e. the system is challenged by the comments from both the positive and negative sides. If legislation and standard procedures are followed for the review of the $1-4$ road development, the system of the $1-4$ development will remain unchanged due to the balance between the positive and negative comments. Policy-wise, the Qieding 1 - 4 road will remain undeveloped and active.

The redistribution of resource, of course, is one part of the social system that is difficult to reach a good balance. The policies and planning of city hall has certain degree of influence on land use and building development, including the operations of a city, national investments, and how much people accept in the process of "public benefits" of city, and consumption activities. Rarely there is only a simple and optimized solution to solve all the problems of a city. However, it is necessary to have further policy planning to prevent a different type of problems.

A series of existing policy and planning options have to have a wise choice. The purpose of the planning for Qieding 1 - 4 road should be regarded as the 
"specifications for the development of social system." As a result, planning is the framework to put the government's policy making system to work. For public benefits, planning can be done for all kinds of reasons. This may in conflict with the overall planning for the goals of a city, because it discloses the adjustments made in response to the various attitudes of people, the market mechanism and the effects generated. For the planning of this Qieding 1 - 4 road, people and the environmentalist groups are debating whose idea or plan is the right one. For the purpose of most plans, it is assumed that the public benefits should incorporate the "overall consideration" of the public or redistribution of resources with the voices of the socially disadvantaged, the poor and the minorities. However, the effectiveness of the goal of these plans should be able to satisfy the various comments needed during the production and reproduction process of a city.

\subsection{Urban Disaster Prevention}

In order to improve a city's livability and prevent disasters, it is necessary to maintain the city's advantages such as climates and geographic features, as well as to reduce or suppress disadvantages such as higher costs of water resource management and collecting and recycling of rainfall and wastewater through wastewater treatment plant. The important issues that may lead to disasters at the sensitive areas in Kaohsiung may include: 1) Threats from the rising sea level and tsunamis due to global climate changes; 2) Threats from misuse of coastal landscapes and ecologic resources and pollution; 3) Over-pumping of groundwater at coastal areas; 4) Public hazards from the development of industrial parks; 5) Competition between water resource protection in catchment areas and other land uses; 6) Lack of water resources and flooding; and 7) City image issues due to air pollution, noises, epidemics and poor traffic for a very long time. This indicates the influence of long-term development of traditional industries on the environmental quality in Kaohsiung, which becomes a serious concern for the development of Kaohsiung City.

Presented in this section is the example of dengue fever, an international epidemic disease that has been plagued Southeast Asia, Central and South Americas. The dengue fever has been in existence ever since its discovery in 1779. For more than 200 years, it has been threatening human being as well as economic development and cities' images. In addition, the global warming allows the disease-carrying mosquitoes to migrate north. On top of that, Taiwan has become an economically and socially liberated country. The interactions with international communities are frequent and that adds the extra difficulty for the control of dengue fever and opens the door for epidemic diseases to come to Taiwan. Kaohsiung has an airport and seaport and is a city of heavy industries. The frequent interactions and local climates are perfect for mosquitoes to thrive. As a result, when a dengue fever case is imported, the entire city is under the threat of dengue epidemics.

There are natural as well as manmade disasters that the City of Kaohsiung has to deal with. The roads of Kaohsiung City are the arteries for the transportation 
of people as well as petrochemical materials. However, this involves the complicated professional knowledge and meticulous operation procedures needed to run a metropolis. Also, open and transparent data judgments are required. Without them, the city is prone to sabotage or out-of-control disaster. The gas explosion at the night of July 312014 is a deadly reminder of how important the disaster control is.

July 312014 around 20:00, some people smelled what seemed to be gas leak and called the fire department. Upon receiving the phone call, the fire department checked with all major gas companies and found no natural gas pipelines at the scene. The firefighter started to spray water at the scene trying to thin out the gas and set up traffic blocks. At that time nobody knew that a large quantity of liquid propene had evaporated and spread along the underground drainage culverts from Sanduo Road to the culverts on Kaixuan $3^{\text {rd }}$ Road and then Sanduo $1^{\text {st }}$ Road and Yixin $1^{\text {st }}$ Road to the north and south. Just around 23:56 July 31, a spark coming out of nowhere triggered a series of explosions. The policemen and firefighters at the scene were injured badly and rushed to hospitals.

Here the equation in Section 3 is used by assuming the external force $(F)$ is the gas explosion, dengue fever and other disasters that create impacts to the daily life of people in Kaohsiung. When the s of the original system is subtracted from the total external force, the system change $(\Delta s)$ is 1 , reference state $\mathrm{R}=1$ and balance state $X=1$, resulting in $s_{X}<s_{R}+\int \Delta s / F$. The original system is destroyed by the new system, or the original system is interfered by external force until it is restored when $s_{X}=s_{R}$. On the other hand, $s_{X}=s_{R}$ when no external force occurs, and the city development remains in its existing course of development. Likewise, during the process of change in a closed absolute external force system, the change of the life system of people in a city is susceptible to external force of natural environment $(N)$ and social scenario $(C)$, which is to say that the extent of dengue fever or gas explosion, the reconstruction, maintenance or disappearance of system fluctuate under the influence of the both, rather than the prevention of occurrence due to appropriate emergency response or reduction of disastrous effects. The lack of how external force works will lead to more casualties.

With the structuration theory in Section, it is assumed that the epidemic control team had disease- carrying mosquitoes under control or the fire department had good communications with companies, and there might be a chance to work together for system multiplication effects for disaster reduction. If the preventive actions are not in place in time or the intervention of power with insufficient knowledge and judgment, the effects generated by the system may be reduced or compromised. If these companies are supervised based on the normal legislation or punishment procedure, they will probably make improvement and the original life system will be restored.

The extent of urban disaster covers industries, pipelines, vehicles and restricted port area. Therefore, the repairs and controls for urban disaster are difference from city to city in terms of complexity and extent, and the effect of dis- 
aster mitigation can be achieved by not just specifying the time limits for response. Modern livability standard often emphasizes on economy and elements of life, such as job opportunities, good housing school and shopping, highly efficient transportation system and sound city finance. The construction of a livable city should, of course, include disaster prevention and mitigation as well as the assistance from disaster prevention industry before responding to the disaster prevention issues that no city can bypass.

The long-term, forward-looking urban policies and constant demands for urban planning allow the urban environment to become more livable and reduce the risks of disaster. The industrial transformation and technical innovation make the use of lands and work environment surrounding a harbor friendlier, and in turn the life management will become fair and just. As a result, on one side of the management of urban and social changes is the balance between social, environmental and economic priorities and strikes, and on the other the harmony among the development of life, land and ecology and self-governance and mutual assistance of communities. From this wider angle, it is clear that social security, health, fair acquisition of housing, community service and entertainment activities can be realized in a continuously developing and livable city with sufficient allowance and cultural/spiritual needs before traditions, values and points of view are transformed from the roots rather than all of these being done while a certain government official is during his/her term in office.

\subsection{System Construction for Smart Phone}

The working-class man finally settles down and tries to restore everything in his smart phone. So he goes to company B to have the LCD screen of his smart phone fixed, which takes only a day. That is to say, it would have been easier to restore everything if he waited, and that is much easier and quicker than buying a new phone and having everything restored for Line groups. A careless rush puts him back to the starting point.

Here the equation in Section 3 is applied to the case of the working-class man mentioned previously. It is assumed that the external forces of system $(F)$ are the negligence of the working-class man and the manmade error due to the lack of service representative's knowledge which lead to the damage to the cell phone, loss of Line groups and eventually the disappearance of the cell phone system (including hardware and software). When the $s$ of the original system is subtracted from the total external force $(F)$, the system change $(\Delta s)$ is 1 , the reference state is $R=1$, the balance state is $X=1$, and then the system becomes $s_{X}<$ $s_{R}$, which indicates the disappearance of the original system. When the working-class man goes to the service center for repair and decides to buy a new cell phone, the reference state becomes $R=1$ and balance state $X=2$, resulting in $s_{X}>s_{R}$, the reconstruction of a new system until $s_{X}=s_{R}$. On the other hand, if there is no external force at all, $s_{X}=s_{R}$ and the cell phone remains the same from the beginning to the end. Similarly, if there is no exchange of external force with the outside world, the system change will be subject to the changes in the exter- 
nal force of natural environment $(N)$ and social scenario $(C)$. The construction, disappearance or maintenance of the cell phone will fluctuate in the influence of the external force of natural environment $(N)$, which is the damage to the cell phone, and social scenario $(C)$ between the working-class man and the service representative. The time for the cell phone repair will be accelerated but it is difficult to restore the original system functions. This is what the 4 examples above are trying to present; i.e. "time" is never the key to solve a problem from the beginning to the end.

By introducing the structuration theory in Section 4, it is assumed that the working-class man has thorough communications with the telephone company or the service representative, there may be a chance for them to work together to facilitate the update of cell phone hardware and the system multiplication effects of re-screening Line groups. However, with the power intervention of time such as the external request for accelerated repair or lack of knowledge for a sound judgment, the effects generated for the system may be reduced or even work against the system. If a normal procedure were followed as the man goes home and find his password before he does anything for the repair, the original state of the cell phone system would have remained intact. The construction of the smart phone system above indicates that the reason to fail achieve the goal established even after a system is built is in fact the lack of knowledge about external force; i.e. the combination of agent and structure. The key is whether the political motivations are understood. Imagine this: what would the world be like if all the smart phones are gone? Do we see the future or go back to present?

We discovered from related cases in this research that the effective solutions for the transportation planning improvement in Kaohsiung Harbor City and land usage of Qieding Path No. 1 - 4 are the creation of highways or paths leading to industrial or residential areas; however, facing the objections from environmental groups, it became, instead, two polar opposite professional views, external forces caused the promotion of the policy to be unsuccessful and it is not because of the length of time, and existing administrative processing system could not be used to finish this. In terms of professional cognition and judgment, the dengue fever in urban disaster prevention or the treatment of petrochemical gas explosion cannot be successfully resolved just because of rapid disaster relief. The reconstruction of the system in smart phones is also like this. In order for effective processing, the focus must be on the influence of external forces and not the length of time, this is also the discovery and verified results of this research through proof of practical cases. Using this principle and through calculated derivation, we will be able to quantify the level of influence in the future and achieve the effect of successfully reducing disasters.

\section{Conclusion}

In the modern living conditions, we are dealing with a perceptive world unlike any one in the human history. However, some people still choose to live locally and ensure the existence of all historical memories in the context of time and 
space (Giddens, 1991). Europe arrived in the bronze age 2000 years before Christ and the civilization of romance began. Midway through the $13^{\text {th }}$ century BC, Mycenae was wiped away from the map by the Dorians and the Greek civilization entered a new era of development. Civilization is the change of cultures. As cultures become convergent, the existence of culture is reduced. When the path of geographic search disappears, it takes human civilization with it. The disappearance of smart phones is just a part of deconstruction and reconstruction of human civilization as a system.

When the smart phone disappears, the working-class man finds that the old friends in one of his Line groups do not even realize that he disappears simply because he just appears in the group without making any ripple. His withdrawal is just the disappearance of one of many factors in the grand system; i.e. he is dispensable. What he is facing is to choose between reconstructing the group and going back to the very beginning (i.e. staying out of that group for good). The key is that the original system will not be restored, or more precisely, whether it needs to be restored. This brings us back to the question of trade-off for external force (the behavior of the working-class man to make a decision), rather than time itself. The assumption in the equation of Section 3 suggests that time is not the decisive actor of dynamic results. That is to say that we are unable to simplify the result of time; instead, we create the difficulty for making a judgment. When it comes to the requirement of 72 hours of golden time for disaster rescue or completion of a construction project required by the head of government, it is basically deconstructing the effective tasks of the entire system.

Two standards are proposed here as the abstract judgment equation for the explanation for construction and change of system by referring to Frank and Mark (1981). First, does the calculation model characterize the experience phenomenon? For this, the importance of open and closed environments to the interactive and correlative roles of the relationship between system and environment is re-explained based on the system equation in Section 3. The second standard is related to the experience value defined. It shows that not using the model may lead to personal judgment and even incorrect analysis. This means that examining the problems in the framework of system process will generate more accurate system conclusions. In this regard, the structuration theory is used in this study to propose examples. The result of interactions between structure and agent is used to describe new external force or more delicately separated system hypotheses and predictions, which may serve as a reference for the development of strategies.

The greatest key to achieve something is how to include external forces in the system. In this study, a new horizon is presented for the study of system models in addition to proposing methods for problem solving. For example, system variables and structure characteristics can be defined at any level of natural environment and social system in order to investigate the influence of a variable on another system, and the effects that may be generated. Particularly, when the concepts of structuration theory are applied, in what conditions a system of 
multiplication will be created? Are some external forces embedded in the system, the cause of the system to appear or disappear at a certain level? What impacts will the disturbance at a given level on the ups and downs of the system at higher and lower levels? Are the functions of the original system maintained?

Also, it is found in empirical analysis that the lack of able and influential external force in a system will not allow the definition of the optimized solution and result for a society or project, because, for the external factors of influence for the system, such as politics, economy, organizational institution conditions, and trading behavior of underground economy, there are too many agents that are checking and balancing on one another, resulting in misplaced resources. A constantly balanced system is not necessarily beneficial to the society. The change or evolution of external force allows the rolling adjustments of system with the dynamics of life. Of course, the key may not be the reconstruction of system. Instead, it is how to adjust and adapt to give a system a useful procedure and way of governance, and to allow life to improve and move forward instead of making a system fit only within an existing framework.

Capitalism feeds on people's desire for benefits for the growth of profits. Profits are won and products abandoned in the process of constant acquisition of resources. There is the lack of ideals when we look at the life of most people even from the social, political and historic philosophical points of view of Conte and Hegel (Li, 1993). The struggles and balancing between one another provide the environment indirectly in which a just civil society emerges Political figures bring changes to society by following personal desires and private motivations, and history will choose the right political figures to achieve the goal of each stage and construct the social system in which we live and survive. As the belief of this study, it is more practical and maneuverable to start from the life system for a better understanding of system.

For the quantification of future system, it is suggested to quantify the external force factors mentioned in Section 5 (such as considering the quantity of black-faced spoonbills at the Qieding wetland as an external force), or combine applied mechanics and the equations of this study. First, the loose particles with zero bonding or coherence force (as internal force of system) between the particles as the ideal loose particles to estimate when the friction boundary between particles begins to move under shear force and the mechanical concepts such as full-scale plastic shearing (as external force) for the agent quantification data of the system. This may be a whole new attempt but helpful for the description of a system.

However, what you need to notice is that this research is a conceptual discussion, we will still encounter many hypothetical data and issue during calculated quantification or the application of data, for example: different materials, angles, environments, and internal forces and friction might cause the derived results to not be the same. In discussing the various phenomena and processing methods in social life, if issues such as politics, economy, and democratic nations are involved, the decisions and results might also not be the same. These will be diffi- 
culties and limitations encountered in future researches, which will also be valuable for researchers to further discuss.

\section{References}

Barry, R. (1994). Systems Thinking/System Dynamics: Let's Just Get on with It. System Dynamics Review, 10, 135-157.

Bourdieu, P. (1984). Distinction: A Social Critique of the Judgment of Taste (Trans. R Nice). London: Routledge.

Bourdieu, P., \& Wacquan, L. (1992). An Invitation to Reflexive Sociology. Chicago, IL: University of Chicago Press.

Cloke, P., Philo, C. \& Sadler, D. (1991). Approaching Human Geography (pp. 93-113). London: Paul Chapman Publishing.

Environmental Protection Administration, Executive Yuan (2002). Final Report for the Study on Motorcycle Travel Patterns and Emission Coefficient in Urban Areas. http://www.epa.gov.tw/public/Attachment/4331450622.pdf

Frank, H., \& Mark, F. B. (1981). What Is a System. Social Networks, 3, 29-40. https://doi.org/10.1016/0378-8733(81)90003-4

Gaventa, J. (2013). Power after Lukes: An Overview of Theories of Power Since Lukes and Their Application to Development. http://www.powercube.net/wp-content/uploads/2009/11/powerafterlukes.pdf

Giddens, A. (1976). New Rules of Sociological Method (pp. 118-126). London: Hutchinson.

Giddens, A. (1984). The Constitution of Society (p. 29, 326). Cambridge: Polity Press; Taipei: Tso-An Publishing House. (Translated by Kang Li \& Meng Li (2007))

Giddens, A. (1991). Structuration Theory: Past, Present and Future. In: Bryant, C.G.A. and Jary, D., Eds., Giddens' Theory of Structuration: A Critical Appreciation (pp. 201-221). London: Routledge.

Gregory, D., Johnston, R. J., Pratt, G., Watts, M. J., \& Whatmore, S. (Eds.) (2009). The Dictionary of Human Geography (5th ed.). Oxford: Blackwell.

Hung, L. T. (2000). Social Doctrines and Political Theories-Introduction to Contemporary State-of-the-Art Thinking (pp. 106-151). Taipei: Yang Chih Book Co., Ltd.

Institute for Information Industry (2014). Almost 70\% of People Are Using Smart Mobile Devices; the Market Is Saturating! IIT FIND: Mobile Device Users Increase by More than a Million in 6 Months; 14.32 Million People Are Swiping into a New Era. New Release. http://www.iii.org.tw/Press/NewsDtl.aspx?nsp_sqno=1475\&fm_sqno=14.

Jary, D., \& Julia, J. (1991). Collins Dictionary of Sociology (p. 664, 774). Glasgow: Harper Collins.

Kant, E. (1996). Collected Works of the History of Rational Criticism (p. 2, 9, 156). Beijing: Commercial Press.

Ku, G. F., \& Zhang, X. Y. (2005). Creation of the Dissipative Structure of Regional Economy System and Evolution Mechanism. Journal of Northeast Normal University, $37,123$.

Levine, D. (1972). On Individuality and Social Forms. Chicago, IL: University of Chicago Press.

Li, J. T. (1993). Sense of History: Introduction to the Historical Philosophy of Hegel (p. 226, 228, 235). Student Bookstore.

Lin-Liao, J. H. (2013). The Interaction between the Port and Kaohsiung City: Economy, 
Institution and Power. City, Culture and Society, 4, 21-35.

Lin-Liao, J. H. (2014). Study for Correlation Dynamic Analysis of Kaohsiung Port City. Unpublished Doctoral Dissertation, Kaohsiung: Department of Geography, National Kaohsiung Normal University.

McConnell, J. V. (1977). Understanding Human Behavior. New York: Holt, Rinehart and Winston.

Miller, J. G. (1965). Living Systems: Basic Concepts. Behavioral Science, 10, 193-231. https://doi.org/10.1002/bs.3830100302

Moos, A. I., \& Dear, M. J. (1986a). Structuration Theory in Urban Analysis: 1. Theoretical Exegesis. Environment and Planning A, 18, 231-252. https://doi.org/10.1068/a180231

Moos, A. I., \& Dear, M. J. (1986b). Structuration Theory in Urban Analysis: 2. Empirical Application. Environment and Planning A, 18, 351-373. https://doi.org/10.1068/a180351

Pacione, M. (2009). Urban Geography: A Global Perspective. London: Routledge.

Paich, M. (1985). Generic Structures. System Dynamics Review, 1, 126-132. https://doi.org/10.1002/sdr.4260010111

Parsons, T. (1937). The Structure of Social Action. New York: McGraw-Hill.

Patrick, G. (2009). Kampung, Islam and State in Urban. Java Publisher, NUS Press.

Richardson, G. P., \& Pugh, A. L. (1981). Introduction to System Dynamics Modeling with DYNAMO. Cambridge: MIT Press.

Robert, A. R., \& Jack, J. K. (2006). Energy and the Environment (2nd ed.). Hoboken, NJ: John Wiley \& Sons, Inc.

Sendhil, M., \& Richard, T. (2000). Behavioral Economics. Working Paper, 27.

Simmel, G. (1905). A Contribution to the Sociology of Religion. American Journal of Sociology, 11, 359-376. https://doi.org/10.1086/211407

Tsai, R. M. (1997). Development and Application of Log-linear Models and Log-Multiplicative Model: Take Social Mobility as an Example. In Yang, W.S. (Ed.), Recent Development and Applications of Quantitative Methods in Social Sciences (pp. 61-102). Taipei: Research Center for Humanities and Social Sciences, Academia Sinica.

Tsai, R. M., \& Lin, D. S. (1999). The “Structure” Concept Used in Taiwan's Study of Stratum: A Preliminary Reflection. Social Science Theories and Localization Symposium (pp. 221-274). Chiayi: Graduate Institute of Sociology of Education, Nanhua University.

Wang, C. C. (2003). Thermodynamics and Statistical Physics (3rd ed.). Taipei: High Education Press.

Wikipedia (2017). Entropy. https://zh.wikipedia.org/wiki/\%E7\%86\%B5

William, H., \& Sewell, J. (1992). A Theory of Structure: Duality, Agency, and Transformation. American Journal of Sociology, 98, 1-29. https://doi.org/10.1086/229967

Zhang, P. (2006). Dynamic Model of Urban Interactive System, Dissertation of Port, Coast and Offshore Engineering. Nanjing: Hohai University, China; Nanjing University. 
Submit or recommend next manuscript to SCIRP and we will provide best service for you:

Accepting pre-submission inquiries through Email, Facebook, LinkedIn, Twitter, etc. A wide selection of journals (inclusive of 9 subjects, more than 200 journals)

Providing 24-hour high-quality service

User-friendly online submission system

Fair and swift peer-review system

Efficient typesetting and proofreading procedure

Display of the result of downloads and visits, as well as the number of cited articles Maximum dissemination of your research work

Submit your manuscript at: http://papersubmission.scirp.org/

Or contact cus@scirp.org 